\title{
O ORIENTE DE FUNAKOSHI NO HORIZONTE DO KARATÊ DESPORTIVIZADO
}

DOI: 105902/01028308 23757

Data de submissão: 31-08-2016

Data de Aceite: 01-11-2016

Milton de Souza Coelho

Universidade Federal do Rio de Janeiro miltsc@gmail.com

\section{Paulo Renato Moreira da Silva Coelho Intellectus prmsc@gmail.com}

\author{
Leandro Nogueira Salgado Filho \\ Universidade Federal do Rio de Janeiro \\ Insf@gmail.com \\ Nilda Tevez Ferreira \\ Universidade Federal do Rio de Janeiro \\ nilda.tevez@gmail.com \\ Jorge Felipe Columá \\ UNISUAM / FAETEC \\ jorgecoluma@gmail.com \\ Felipe da Silva Triani \\ Faculdade Gama e Souza \\ felipetriani@gmail.com
}

Resumo: O oriente de Funakoshi se projeta no karatê atual. Nesse viés, os deslocamentos de sentido da desportivização geram valores mesclados do Bushido que unem valores antigos e novos. Com isso o mestre perde autonomia diante da Federação que tende a investir numa estética padronizada e na educação do movimento. Isso acelera a desconstrução da prática que privilegiava o kata e o Bushido tradicional. Nesse sentido, objetiva-se analisar indícios de emergência de novos códigos culturais, caracterizadores de éticas mitigadas, como alternativas à ética do Bushido no sentido tradicional. Para atingi-lo, foi realizada uma pesquisa híbrida em que praticantes de Karatê Shotokan são questionados e entrevistados a partir do $1^{\circ}$ Dan filiados à Federação de Karatê do Rio de Janeiro. Portanto, o estudo mostra que a ética do Bushido se desloca em direção a outros valores, ancorada na força imaginária do Bushido tradicional que pavimenta o campo para a legitimação de novos valores.

Palavras-chave: Karatê. Ética. Estética. Deslocamento de Sentido. 


\section{Introdução}

O uso que o governo japonês fez da figura do Samurai e do seu código de honra, o Bushido, na era da restauração Meiji, 1868 (SAKURAI, 2007), foi decisivo para a reificação da figura do Samurai e a consequente sobrevivência deste princípio ético (Bushido) que se propagou pelo mundo através das artes marciais.

Atualmente, considerando o contexto brasileiro, a imagem mística do Samurai e seu código de ética são trazidos na bagagem dos imigrantes japoneses, e passam a servir de modelo para o praticante de artes marciais, cuja conduta se norteia por seus atributos e seu imaginário (YONEZAWA, 2010).

Nesse sentido, tomando como referência o Karatê Shotokan, foi investigado se em tempos de modernidade tardia (GIDDENS, 2009), se ainda há predominância de um tipo de ascetismo capaz de engendrar um "espírito" unificador para essa modalidade, ou se essa força uniformizadora não estaria a apresentar fissuras em suas "estruturas", propiciando a emergência de éticas mitigadas.

Nessa direção e à guisa de esclarecimento, a ética do Bushido trata-se, portanto, do caminho do guerreiro, e funciona ainda como um imperativo ético capaz de modular as condutas no cotidiano das artes marciais japonesas abrasileiradas (YUZAN, 2003). Porém, com base no cotidiano das academias do Rio de Janeiro, que possuem o Karatê Shotokan, foram investigadas as "pequenas verdades", que no confronto com uma "produção racionalizada", os consumidores de artes marciais fabricam (CERTEAU, 1994).

Portanto, esse estudo buscou o discurso dos praticantes de Karatê Shotokan, filiados a Federação de Karatê do Rio de Janeiro, com a intenção de identificar convergências e/ou divergências em relação à concepção de ética do Bushido. E, nessa perspectiva, o objetivo foi analisar indícios de emergência de novos códigos culturais caracterizadores de éticas mitigadas, alternativas à ética do Bushido no sentido tradicional. Além disso, também a contribuição dos faixas pretas, na preservação dos códigos culturais (etiqueta) referentes à ética do Bushido no Karatê Shotokan, foi valiada. 


\section{O Percurso Metodológico}

Adotou-se um estudo de caráter exploratório, tendo o método híbrido com base em dois pilares: a)Análise transversal, operada através de um questionário anônimo, com a utilização de perguntas abertas e fechadas, inspirada na escala Likert; b) Análise de discurso, em que além dos dados do questionário, entrevistas foram realizadas com o intuito de apreender deslocamentos de sentidos nas palavras dos praticantes de Karatê Shotokan em relação à ética do Bushido, ancorados nos pressupostos do imaginário social, na perspectiva de Ferreira (2003).

Com foco numa análise transversal, fez-se uso da coleta de dados por meio de um questionário com perguntas abertas e fechadas, que foram analisadas com base numa escala de opinião e atitudes, em que a referência foi a Escala de Likert (ou escalas somadas) com cinco pontos, assim discriminados: (1) Concordo totalmente, (2) concordo em parte, (3) não tenho ideia formada, (4) discordo em parte e (5) discordo totalmente. Vale registrar que a opção por esse instrumento foi porque ele estabelece que os entrevistados indiquem grau de concordância ou discordância, com declarações relativas à atitude que está sendo medida.

Eleitos, como foco desse estudo, apenas os profissionais "faixas pretas", que atuam no ensino do karatê nas academias filiadas à Federação de karatê, situadas na cidade do Rio de Janeiro, que têm mais de cinco anos de efetivo ensino regular de karatê.

O levantamento de dados foi feito por meio de um questionário, que visava diagnosticar a percepção dos praticantes de Karatê Shotokan do Rio de Janeiro (federados) sobre o conceito Bushido. As entrevistas, então, foram realizadas posteriormente aos questionários emitidos.

O universo da pesquisa foi constituído por 55 faixas pretas associados à Federação do Rio de Janeiro, que responderam ao questionário e participaram da entrevista. Assim, a amostra foi composta por praticantes de Karatê Shotokan, faixas pretas (a partir do $1^{\circ} \mathrm{Dan}$ ), com idade entre 20 e 70 anos, ligados à atividade de ensino. 


\section{O Bushido na Literatura}

De modo geral, a literatura tem tratado a ética do Bushido como se fora um construto universal, descolada da dinâmica do cotidiano (CERTEAU, 1994). Assim sendo, estudos como os de Yuzan (2003), Barreira e Massimi (2003), Ratti (2006), Drigo (2009), Yonezawa (2010), entre outros, em que pese à relevância desses estudos, não têm priorizado o processo de apropriação efetivado pelos diferentes grupos de praticantes. Em consequência, a análise dos deslizamentos de sentidos produzidos pelo processo de apropriação, quer sejam eles, superficiais ou profundos (COELHO, 1995), não tem sido focalizada.

Consequentemente, năo percebem que no confronto com as "produções racionalizadas", os consumidores de artes marciais deslocam os sentidos das verdades universais e fabricam outra perspectiva: de corpo e de ética. Isso para dar conta da dinâmica do seu cotidiano. Tal elaboraçăo corresponde a uma (CERTEAU, 1994, p. 39)

outra produçăo, qualificada de consumo: astuciosa,dispersa,mas ao mesmo tempo (...) ubiquamente silenciosa e quase invisivel ,pois năo se faz notar nos produtos próprios mas nas maneiras de empregar os produtos impostos por uma ordem (...) dominante.

Isso nos leva a sugerir que a ética do Bushido, enquanto fio integrador das artes marciais desportivizadas, emerge não necessariamente de forma ostensiva, incisiva, mas sim dispersa, nos entremeios, nas fissuras, conferindo à formação um ar dúbio de tensão e distensão, ora negando, ora assumindo o confronto com esse fio integrador e unificador, sob uma marcação em direção a uma maneira sempre original de lidar com os produtos impostos pela ordem desportivizada e desportivizante das artes marciais, cuja função tende a indicar a homogeneizaçăo de condutas.

A análise dessas lógicas se tornou vital para que seja apreendido o modus operandi dos artistas marciais, ou seja, o modo como inscrevem a ética do Bushido no seu fazer cotidiano. É necessário compreender como na atualidade os possíveis esquemas operacionais (construídos pelos praticantes) se comportam, visando desvelar categorias comuns e o modo como essas categorias se articulam para explicar o conjunto dessas práticas.

Isso posto, opera-se uma "desnaturalizaçăo" da leitura de formaçăo do artista marcial 
contemporâneo que é, via de regra, concebida como homogęnea e padronizada.

Ratifica-se aqui a crença na idéia de formaçăo vinculada à tensăo exercida entre a ética do Bushido, enquanto marca constituitiva das artes marciais japonesas, e o modo de apropriaçăo cotidiana realizada pelos praticantes, algo que se torna vital para que se entenda a lógica de formaçăo nesse campo atualmente. Nesse viés, percebe-se que:

Os usuários fazem uma "bricolagem" com e na economia dominante, usando inúmeras e infinitesimais metamorfoses da lei, segundo seus interesses próprios e suas próprias regras. Desta atividade de formigas é mister descobrir os procedimentos, as bases os efeitos, as possibilidades (CERTEAU, 1994, p. 40).

Cabia, pois, investigar essa "ética em açăo", que tende a singularizar o processo de formaçăo, por força das contradiçőes existentes em cada espaço de apropriaçăo, em particular. Esse viés de análise ajuda a compreender a dinâmica do cotidiano e o modo como a formaçăo marcial se articula com a perspectiva ética dominante.

As alteraçőes perpetradas pelas ligaçőes simbióticas construídas entre a ética do Bushido, enquanto fio integrador, e o movimento dos sujeitos que com ela dialogam, contribuem para a ampliaçăo do conhecimento, no que tange as transformações profundas ocorridas no "arcabouço imaginário" das artes marciais na atualidade.

Essa perspectiva, ajudou a compreender que o simples fato de existir uma ética do Bushido, como fio integrador das práticas e condutas no campo das artes marciais japonesas, não representa garantia de que ainda essas artes sejam regidas por essa ética, ou seja, que ela opere plenamente como referencial das práticas.

\section{O Bushido no imaginário dos praticantes de Karatê Shotokan}

Os valores assinalados pelos respondentes sinalizam a incidência de possíveis indicadores de escalas valorativas emergentes, que pela própria dinâmica da sociedade atual não oferecem garantias de que serão legitimados como referenciais de prática de grupos maiores. Esses valores são um retrato do grupo naquele momento, algo com possibilidade de permanecer vivo ou não, dependendo da dinâmica de organização de prática do grupo.

Esse referencial ético continua vivo em suas práticas, modulando desde o respeito 
à figura do mestre (que simbolicamente tem relação com o sagrado), passando pela reverência ao dojo, nome que designa uma área sagrada, até o cumprimento a Funakoshi que revive o culto aos antepassados, marca singular do xintoísmo japonês.

Estas marcas servem de estofo para que o Bushido, marca inconteste do oriente de Funakoshi, inscreva-se no horizonte do karatê desportivizado na atualidade. Nesse viés, observa-se que a relação conflituosa entre o instituído e o instituinte emerge um sentido de Bushido não passível de ser compreendido sem uma investigação que vá além da superfície das palavras. Pois, nessa relação se encontra o novo e o antigo. $O$ ponto de mutação do discurso ai se localiza. A propósito, Pecheux, citado em Orlandi (1993, p. 13), observa que:

Não há ritual sem falhas, (...) Por isso é possível a ruptura. Instauração de uma nova ordem de sentidos. O que o caracteriza como fundador - em qualquer caso mais precipuamente neste - é que ele cria uma nova tradição, ele re-significa o que veio antes e instituiu aí uma memória outra. É um momento de significação importante, diferenciado. O sentido anterior é desautorizado. Instala-se outra tradição de sentidos que produz os outros sentidos nesse lugar. Instala-se uma nova filiação. Esse dizer irrompe no processo significativo de tal modo que pelo seu próprio surgir produz sua memória.

A reapropriação do Bushido pelas federações propicia a emergência de outros sentidos dessa vertente ética. Os fragmentos recolhidos do ritual anterior servem de base para a emergência de uma ordem outra de sentidos e práticas. O já dito funciona como uma ponte. Ele "sustenta o sentido que surge e se sustenta nele" (ORLANDI, 1993, p. 13).

Isso implica dizer que outros sentidos de Bushido podem ser sugeridos pelo discurso dos praticantes. Além disso, poderão ser também sustentados por uma ordem outra de sentidos que Ihes confira coerência e eficácia.

Esse novo viés ético tende a se consolidar como referencial de conduta dos praticantes porque, como já foi dito, produz um efeito de reconhecimento e aceitação ancorado na combinação de valores do Bushido, tradicional com o desportivizado, algo que contribui para a sua legitimação.

Assim, visando colher pistas que apontassem na direção desses atributos, cuja força simbólica pode contribui ainda para dar sentido ao fazer dos praticantes de karatê, foi proposto aos informantes que indicassem marcas que pudessem indiciar o praticante, que seguissem os princípios do Bushido, em oposição com outra questão em que indicassem 
também marcas que fosse possível identificar o praticante que não seguiria os princípios do Bushido.

A expectativa era que os informantes apontassem marcas apenas voltadas para o karatê atual aonde a força da desportivização paulatinamente vai definindo outro perfil de praticante. No entanto, as respostas mostraram conteúdos bastante diversificados e de certo modo até inusitados.

A partir dessas características elencadas, uma estrutura triádica foi construída onde valores voluntariamente revelados pelos informantes foram associados a três níveis de relação simbólica com o Bushido, a saber: os valores mais centrais que foram associados ao karatê da era Tokugawa notadamente a partir do século XVII, quando o Bushido se consolidou como imperativo ético nos moldes Kantianos; os intermediários ao karatê da Era Meiji (1868), quando ocorreram os deslocamentos de sentidos do Bushido promovidos por Funakoshi, e os periféricos, ao karatê da Era contemporânea (pós-guerra) em que à força de Eros cada vez mais foi condicionada aos limites e possibilidades de exploração das reservas pedagógicas do karatê.

Embora o quantitativo de emissões não tenha sido considerado como foco dessa pesquisa, percebeu-se que a frequência de emissões de alguns atributos elencados pelos informantes apontou na direção do que se pode chamar de permanências de pedaços de memória temporalizadas (ORLANDI, 1992), cujos sentidos não só figuravam como balisadores das condutas no karatê como também pareciam funcionar como "amarras", como ancoragens garantindo a sobrevivência de vínculos que ligavam o karatê ao mundo das artes marciais tradicionais. Essa memória constantemente atualizada aproxima-se do conceito de recursividade de Giddens (2009, p. 3) que observa que:

As atividades sociais humanas, à semelhança de alguns itens auto-reprodutores na natureza, são recursivos. Quer dizer, elas não são criadas por atores sociais mais continuamente recriadas por eles através dos próprios meios pelos quais eles se expressam como atores. Em suas atividades, e através destas, os agentes reproduzem as condições que tornam possíveis essas atividades. (...) a ação humana acontece como uma durée, um fluxo contínuo de conduta, à semelhança da cognição.

Dentre os valores apontados pelos informantes se destacaram alguns que foram apontados como marcas identificadoras do praticante que seguem os princípios do Bushido. 
Baseado em uma espécie de ontologia tempo - espacial (GIDDENS, 2009), que funciona como eixo articulador das praticas sociais, os informantes convergiram no sentido de apontar valores tais como: fidelidade, disciplina, etiqueta, respeito, humildade como valores essenciais ao praticante que seguem os princípios do Bushido.

É como se um arquétipo do Bushi (guerreiro) permanecesse todo o tempo como imagem- referência, propiciando a emergência desses valores e de um perfil de praticante, sempre tributário da imagem do samurai.

Curiosamente, esses valores historicamente figuram não só como sustentáculos do discurso ético do karatê, mas também como principal argumento dos textos específicos de artes marciais, filmes e animes largamente divulgado hoje em dia.

Ao apontarem esses valores os praticantes resgatam, inconscientemente, seus vínculos ancestrais com as artes marciais. Tais valores remetem ao Bushido tradicional e são responsáveis pela garantia da legitimidade do karatê como arte marcial.

No nível intermediário, os informantes apontaram um conjunto de valores que transitam entre a desportivização e o karatê tradicional. Nesse viés, valores tais como: autocontrole, respeito à vida, serenidade, técnica, modo de fazer o kata, cortesia, postura e autoconhecimento emergem como indicadores de uma relação de transição entre o karatê tradicional e o desportivizado.

No nível externo, que corresponde ao discurso mais contemporâneo, observouse a emergência de atributos diferentes que remetem mais ao desporto e menos as artes marciais no sentido tradicional. Nessa perspectiva, valores tais como: competição exacerbada, respeito ao próximo e a natureza, manter mente boa; boa forma, "espírito", postura, cumprimentar os outros, atitude na luta, esforçar-se para conseguir seus objetivos, conteúdo intelectual, gratidão ao mestre, boa saúde, solidariedade entre outros, aparecem como valores um pouco fora de lugar em relação à prática efetiva das artes marciais.

A impressão que fica é que a desportivização causa um afastamento tão grande em relação ao foco originário das artes marciais que os faixas pretas, mesmo tendo uma sólida formação, já não relacionam a prática do karatê a uma formação ética proveniente da tradição do Bushido. A emergência de valores como: "espírito" atitude na luta, postura, ao lado de atributos, tais como: boa forma, cérebro reptiliano ativo, mente boa e boa saúde, 
mostram que aparentemente está em curso uma mudança que implica a incorporação de novos atributos ao lado de valores ligados à arte marcial, num sentido mais tradicional. De certo modo, isso implica a perda de sentido de alguns valores fundamentais na tradição das artes marciais tradicionais como, por exemplo, a figura do mestre, que embora tenha ainda muito prestígio entre os praticantes, caminha para uma perda de sentido como figura "sagrada" no karatê. Na dimensão prática, de forma mais específica, observa-se que o ikken hissatsu (matar com um só golpe), que fundamentaria a postura do lutador diante de seu oponente, despertando nele o "espírito do guerreiro", já não é sequer identificado pelos praticantes.

Os informantes se referem apenas a um vago e duvidoso "espírito", e a uma provável "postura" como atributos identificadores do praticante que segue os princípios do Bushido.

A impressão é que a proficiência técnica se desarticula da base moral, fazendo com que valores mais tradicionais sejam desprestigiados em favor de novos valores emergentes, algo que ao que tudo indica configura outro caminho de formação bem diferente dos desígnios perspectivados por Funakoshi quando se apropriou do Bushido no inicio do século passado.

\section{Thanatos e Eros: a desportivização do karatê em três atos}

O estudo também revelou que de forma subliminar uma luta intestina se desenrola entre Thanatos e Eros. Nesse sentido, trabalhou-se com essas formas metafóricas com o escopo de designar as forças simbólicas conflitantes que comandam o processo histórico de desportivização do karatê.

A discussão sobre esse conflito de base, que marca todo o movimento de transformação das artes marciais, torna-se estratégica porque a tensão que esse conflito cria interfere na organização da gestualidade e na construção das escalas valorativas dos praticantes.

Destacou-se como artifício para ilustrar essa relação conflituosa três momentos fundamentais no processo de estruturação desse campo de atividades, a saber: o primeiro, refere-se ao período da era medieval japonesa que figura como base de sustentação das artes marciais tradicionais; o segundo, trata-se a era moderna que funciona como alicerce da desportivização do karatê shotokan, cuja gênese remete à era Meiji no Japão 
(1868); e o terceiro, remete a era do pós-guerra, que transformações sociais, culturais e políticas interferiram no processo de desportivização do karatê, sugerindo a acentuação de deslocamentos de sentidos nessa arte marcial.

$1^{\circ}$ Ato

No primeiro momento que correspondia à era do xogunato (era medieval) com base na literatura de Ratti (2006), Sakurai (2007) e Yuzan (2003), é observado que Thanatos reinava absoluto no coração das artes marciais, não havendo conflito, pois o praticante tinha ainda "licença para matar", já que durante o xogunato os samurais mantiveram alguns privilégios que só foram totalmente suprimidos por ocasião da era Meiji (1868). Isso implica dizer que o ikken hissatsu (matar com um só golpe) era a pedra de toque do processo de treinamento dos praticantes. A propósito, referindo-se ao modus operandi do artista marcial da era do xogunato Reid e Croucher (2010), tomando como referência a ideia de que lutar era sinônimo de matar ou morrer, recorria-se às palavras de um mestre da espada do século XVII, que apelava para a "humanidade" dos espadachins a fim de preservar a vida dos contendores, observando que:

O perfeito espadachim evita brigar e lutar. Lutar para nós significa matar. Como pode um ser humano levar-se a matar outro ser humano? (...) É abominável que alguém pense o tempo todo em lutar e vencer. Somos seres dotados de consciência moral; não vamos nos rebaixar ao estado dos animais. De que serve tornar-se um grande espadachim se perde, nesse processo, a própria dignidade humana? A melhor de todas as coisas é vencer sem lutar (REID; CROUCHER, 2010, P. 13).

Essa convivência constante com a possibilidade concreta da morte marcando o cotidiano dos praticantes de artes marciais implicava a necessidade de existência de um forte código de ética que coibisse os excessos e preservasse a vida. Não admira que valores como disciplina, lealdade, fidelidade, respeito, honra, etiqueta e autocontrole, entre outros, citados pelos informantes, figurassem como princípios norteadores desses códigos de conduta naquela época. Todo e qualquer deslize poderia desaguar num conflito que poderia levar à morte de um dos combatentes. Dhoquois (1993) a propósito refletindo sobre a violência, observam que: 
Existe uma correlação entre a intensidade da violência social e a importância atribuída aos códigos de cortesia? Em outras palavras, a polidez não seria o oposto da violência, seria sua forma socializada. O Japão e a Inglaterra, sociedades civilizadas dão prova disso (p.125).

Isso confere aos códigos de ética, como o Bushido, uma função social estratégica, já que o seu cumprimento contribui para a manutenção da violência em níveis "aceitáveis", porquanto deslocam a violência da dimensão física para a simbólica.

$2^{\circ}$ Ato

No segundo momento, que corresponde à era moderna, Thanatos entra em conflito com Eros, marca inconteste da desportivização nos moldes ocidentais. Esse conflito vai paulatinamente transformando a ideia de autocontrole de si para controle das emoções visando à preservação do outro. Vale frisar que não fazia parte do "espírito" das artes marciais antigas a benevolência e o sentido de preservação da vida do outro. O "espírito" das artes marciais, regido por Thanatos, sugeria evitar o combate por que sabia da sua letalidade. Eis porque a era Meiji (1868) figura como um marco no processo de deslocamento de sentidos do karatê de Funakoshi, porquanto a partir desse momento ele passava a incorporar de forma sistemática o ideal de preservação da vida, além do flerte com a competição. Ao dialogar com o arcabouço imaginário do desporto, o karatê teve que fazer concessões tanto na sua estrutura pedagógica como na sua dimensão ético estética.

Eros exige o concurso de novos valores, alguns em clara oposição aos desígnios do karatê no sentido tradicional. Nesse viés, ao deslocar o sentido da prática para o campo da preservação da vida, Eros sufoca Thanatos que cada vez mais é forçado a se retirar para o campo simbólico, onde cada vez mais tem que guardar os golpes considerados mortais acessíveis apenas a um seleto grupo de mestres na arte de lutar. A faixa preta, nesse sentido, parece simbolizar a entrada nesse mundo em que Thanatos ainda transita como possibilidade de atuar no campo real, embora de forma remota.

A propósito, refletindo acerca dessa dimensão simbólica onde Thanatos se esconde nos rituais e nos gestos, Dhoquois (1993) instiga a pensar a ética do Bushido como um 
código de polidez, uma forma de minimizar a violência através do investimento em rituais de convívio. O gentleman e o samurai, nesse viés, tem algo em comum, já que emergem como subprodutos de rígidos códigos de honra que exigem uma permanente vigilância, um constante controle de si mesmos. Dhoquois (1993) lembra como na cultura japonesa certa geografia da honra e uma estética da violência sobrevivem através de gestos e rituais, tendo Thanatos como referência simbólica permanente.

Recordando a celebre peça: "kanadehon Chushingura" de 1748, a autora ressalta que depois de vingarem seu mestre todos os samurais se suicidavam, mostrando que (DHOQUOIS, 1993, p. 132) “o seppuku não é sentido como uma violência, mas antes como um derradeiro ato de polidez dotado de um derradeiro refinamento".

Dhoquois (1993) enfatiza que há no Japão uma forte correlação entre ética e a estética, e que Thanatos é o fio que une e tece essa trama. Todavia, inspirados na autora, pode-se dizer que a arte marcial nesse sentido não é apenas um conjunto de movimentos, é uma configuração estética regida por uma orientação ética.

$3^{\circ}$ Ato

O terceiro momento, que corresponde ao pós-guerra, representa o primado de Eros. Assim sendo, se no estágio anterior a força de Thanatos ainda marcava fortemente a prática do lutador que a todo o momento reivindicava para si a força do espírito do guerreiro que poderia ainda dar a seus punhos a potencia fulminante do ikken hissatsu, no estágio atual essa possibilidade se torna ainda mais remota, já que Eros triunfa sobre Thanatos e institui a primazia da vida.

O interdito do corpo do outro sinalizado pela rigidez da regra que pune aquele que toca ou fere o oponente, ainda que superficialmente, define os contornos da prática do karatê sob a tutela de Eros. Assim, novos atributos (boa saúde, boa forma) passam a figurar como possibilidades no horizonte dessa nova prática. Além disso, o karatê passa a investir também cada vez mais na "competição exacerbada" (info11), algo que de certa forma reflete o padrão da sociedade atual, onde contraditoriamente ao lado de valores como respeito ao próximo, há o incentivo à competição desenfreada e a transformação do caratê num produto capaz de vender desde o "espírito" do samurai (nas academias através da prática 
do karatê), até filmes, livros, anime e jogos de videogame.

Portanto, afirma-se que nesse estágio a desportivização significa o sufocamento de Thanatos, um caminho sem volta, já que há um conflito de base que torna Thanatos cada vez mais incompatível com o estilo de vida atual que prima pela boa forma e pela preservação da vida.

Nesse contexto, o grande desafio das artes marciais na atualidade será manter vivo o espírito de Thanatos, porquanto sem ele a prática das artes marciais perde o sentido, fragiliza-se e fenece.

Significa dizer que a força desportivizante poderá sufocar Thanatos, escondê-lo, reduzi-lo a fragmentos simbólicos, mas jamais exterminá-lo, porque a arte marcial só existe porque Thanatos está vivo! Ele vive na prática e no imaginário das artes marciais, exterminá-lo significaria definitivamente matar o samurai que existe em cada praticante e, consequentemente, extinguir definitivamente a prática das artes marciais.

\section{À Guisa de Conclusão}

Analisou-se nesse estudo como o oriente de Funakoshi se projeta no karatê atual. Foi possível ainda observar que o karatê, como as demais artes marciais japonesas, permanece tributário da imagem Thanatos que estabelece os limites e possibilidades de organização, e funcionamento da prática. Contudo, o estudo indica que Thanatos está fragilizado diante da força de Eros que atua como referencia inconteste dos desportos na atualidade.

Por outro lado, os resultados indicam que o deslocamento de sentido acentuado pela desportivização nas artes marciais, sob a tutela de Eros, vem provocando a emergência de novos valores associados a uma versão mesclada de Bushido que contemplam a simbiose entre valores antigos e novos. Isso traz embutida a figura de um novo praticante que tende a não privilegiar o Bushido no sentido clássico.

Essa nova perspectiva também desloca a figura do mestre que perde autonomia frente à força unificadora da Federação, que tende a investir numa estética padronizada e numa formação com foco na educação do movimento. Contudo, pode-se dizer que o movimento de reapropriação das artes marciais, operado pelas academias, preservou razoavelmente 
as estruturas simbólicas primordiais de formação marcial da era feudal, resguardando o mestre como figura sagrada.

Nesse viés, a figura do "mestre" que passou a ser o modelo ideal de desempenho, de proficiência técnica e probidade, diferentemente dos demais professores cuja prática não os singulariza, nem o coloca em relação com o sagrado, assume ainda um papel estratégico na formação do praticante que "naturalmente" o concebe como alguém que está num patamar diferente do professor.

Assim, a academia, hoje, é uma espécie de "templo" onde a força da figura carismática do "mestre" de artes marciais opera a transposição de barreiras culturais implicando formas mescladas de intervir sobre o corpo. Desse modo, rudimentos da civilização ocidental fundiram-se com elementos do modo de vida oriental, criando no praticante uma maneira singular de "olhar o espaço de prática" e a intervenção corporal.

Esse processo eleva o "mestre de artes marciais" a uma condição especial remetendo a relação professor - aluno à dimensão quase religiosa de "mestre" - "discípulo".

Por essa via, o artista marcial brasileiro incorporou a idéia de sacrifício como condição para galgar o patamar de "mestre", em que a submissão do corpo a exercícios exaustivos acaba sendo aceita como natural e necessária, como se o corpo precisasse de uma “expiação" para se purificar e merecer a condição almejada de "escolhido" (WEBER, 2004).

Essa ligação do mestre com a dimensão religiosa, que por sua vez exige um lugar sagrado, é atestada por Ratti (2006, p. 482) quando apoiado em Dumoulin, registra que:

O Zen foi a base das artes marciais do Japão Feudal, que deu à doutrina do bujutsu uma teoria e uma filosofia para explicar e justificar a prática das artes marciais, e que isso deu ao bujin disciplinas apropriadas para desenvolver um forte caráter e personalidade. (...) os bushi costumavam entrar em templos Zen e usar salas de meditação onde senhores nobres e cavalheiros periodicamente se retiravam para se preparar mediante uma meditação para sua vocação militarp.

Essa densa e longa relação construída entre a arte marcial e o budismo tem garantido, na atualidade, a relativa preservação do lugar de prática como espaço sagrado, o que contribui simbolicamente para o reforçamento da aceitação da relação professor-aluno na dimensão Mestre-Discípulo.

Essa condição de ser, cuja prática deriva de uma relação histórica com o sagrado, 
explica de certo modo porque o "mestre" não prima muito por uma avaliação objetiva do desempenho dos praticantes, podendo levá-lo a quase exaustão, se assim o desejar, pois é o seu olhar que determina quando o "discípulo" (artista marcial) está pronto. Ele reproduz um tipo de relação que sobrevaloriza a prática, em que os "aprendizes em essência aprendem fazendo" tal como ocorria nas escolas de ofícios. O aluno nesse caso vincula a prática à imagem valorizada da figura do "mestre", o que confere uma dimensão de atividade formativa (DRIGO, 2009).

Nesse viés, o mestre propunha um currículo diferenciado baseado na sua vivência, no seu caminho de formação. Em contrapartida, a federação embora ainda preserve a figura simbólica do mestre, vem em direção contrária, propondo um o currículo indiferenciado que tendesse a fragilizar a intervenção do mestre que com base no kata e num grau de relativa autonomia estabelecia seu caminho singular de formação.

Isso contribui para acelerar a desconstrução de uma prática que tinha no gesto sua fonte de transformação do ser em si, com foco na prática do kata. Vale lembrar que na questão de número 15, quando perguntamos qual o peso que deveria ser atribuído ao kata numa escala de 0 a $100 \%$, apenas $14 \%$ dos faixas pretas concordaram totalmente que o kata deveria predominar como ferramenta pedagógica na formação dos praticantes iniciantes.

Outro ponto importante é quanto ao posicionamento dos faixas pretas quando estimulados a diferenciar o praticante que segue os princípios do Bushido, daquele que não segue. Notou-se, nesse item, uma forte frequência de indicadores, remetendo as ideias de respeito e disciplina que fazem parte do núcleo de formação da identidade do samurai. Embora não fosse o objetivo desse estudo, foi notável observar que "respeito" teve 20 emissões e "disciplina" 13, como referenciais identificadores do praticante que segue o Bushido; e como marca do que não segue, 15 respondentes admitiram o tópico frasal "falta de respeito”, e 8 admitiram “ indisciplina”, todos como marcas relevantes.

Esses dados, embora não sejam conclusivos, sugerem que por alguma razão a relação mestre discípulo está sendo afetada, pois a ideia de respeito está fortemente vinculada à figura emblemática do pai, que nas artes marciais ganha a conotação simbólica de mestre (Osho). Ora, se o respeito é prioritário na identificação daquele que segue os caminhos do Bushido, como assinalaram os "faixas pretas", e se como afirmam há falta de respeito, 
penso que a base de sustentação da cadeia de formação do artista marcial está fragilizada, ou pelo menos passando por um delicado processo de transformação, cujos laivos não foram ainda adequadamente identificados.

Por outro lado, ao verbalizarem que há falta de disciplina, isso também reforça a ideia de fragilidade da figura do mestre, já que ele deve funcionar como referencial de construção da disciplina. Tais dados, não são conclusivos, mas sugerem mudanças no imaginário das artes marciais, que remetem a alterações no projeto pedagógico das artes marciais, cuja base historicamente sempre esteve centrada na figura do mestre guardião e disseminador da ética do Bushido.

Finalmente, o estudo mostra que a ética do Bushido se desloca em direção a outros valores, ancorada na força imaginária do Bushido tradicional que pavimenta o campo para a legitimação de novos valores.

Nesse contexto, o grande desafio das artes marciais, na atualidade, será manter vivo o espírito de Thanatos, já que a tensão com Eros tende a fragilizá-lo, reduzindo a sua credibilidade e legitimidade como referencial mor das artes marciais. Nesse caso, o que está em jogo é a possível perda de sentido das artes marciais no mundo atual.

Pode-se dizer, nesse caso, que Funakoshi garantiu a sobrevivência simbólica de Thanatos, mas teve que abdicar da ética do Bushido, tradicional como imperativo ético, favorecendo a emergência de éticas mitigadas e práticas, que não priorizam mais a formação integral e o desenvolvimento da estética da sensibilidade.

A sobrevivência do karatê, como arte marcial, legitima com foco nas suas tradições e valores que dependem do essencial dialogo com Thanatos, que ironicamente a ascensão de Eros tende a sufocar; e por outro, a sobrevivência legitima da figura do mestre, cuja autonomia precisa ser resguardada sob pena de se empurrar o karatê para o mundo do sem sentido, atividade física banal, ordinária, simples alegoria. 


\section{REFERÊNCIAS}

BARREIRA, C.R. A.; MASSIMI, M. As Ideias Psicopedagógicas e a Espiritualidade no Karatê-Do segundo a Obra de Gichin Funakoshi. Revista Psicologia: Reflexão e Crítica. 2003, v.16, n. 2, p. 379-388.

CERTEAU, M. A Invenção do Cotidiano. Vozes: Petrópolis, RJ, 1994.

COELHO, M. S. Toque-Boxe: uma proposta de boxe não violento. (Dissertação de Mestrado), PPGEF, Universidade Gama Filho, Rio de Janeiro, 1995.

DHOQUOIS, R. de. A Polidez Virtude das Aparências. Porto Alegre: L\&PM, 1993.

DRIGO, A. J. Lutas e Escolas de Oficio: analisando o judô brasileiro. Motriz, Rio Claro, v. 15, n. 2, p. 396-406, abr/jun, 2009.

FERREIRA, N.T. Esporte, jogo e imaginário social. Rio de Janeiro: Shape, 2003.

FILHO, L. N. S. Qualidade de Vida no trabalho do professor de educação física: Um estudo sobre a decência laboral em academias a partir do ponto de vista docente, Tese de Doutorado. UGF, Rio de Janeiro, 2006.

GIDDENS, A. A Construção da Sociedade. São Paulo: Martins Fontes, 2009.

ORLANDI, E. P. As Formas do Silêncio. Campinas: EdUnicamp, 1992.

ORLANDI, E. P. Discurso Fundador. Campinas: Pontes, 1993.

RATTI, O. Segredos dos Samurais: As Artes marciais do Japão Feudal/Oscar Ratti e Adelle Westbrook. São Paulo: Madras, 2006. 
REID, H.; CROUCHER, M. O caminho do Guerreiro: O paradoxo das artes marciais. São Paulo: Cultrix, 2010.

SAKURAI, C. Os Japoneses. São Paulo: Contexto, 2007.

WEBER, Max. Ética protestante e o Espírito do Capitalismo. São Paulo: Companhia das Letras, 2004.

YONEZAWA, F H. Algo se move: um elogio filosófico ético à prática do combate como arte e educação. Motriz, Rio Claro, v. 16, n. 2, p. 348-358, abr/jun. 2010.

YUZAN, D. Bushido: O Código de Honra do Samurai. São Paulo: Madras, 2003. 


\section{THE FUNAKOSHI'S EAST INTO THE SPORT KARATÊ'S HORIZON}

Abstract: The East Funakoshi projects in the current karate. In this bias, the direction of displacement sportification generate mixed values of Bushido that unite old and new values. Thus the master loses autonomy in the Federation that tends to invest in a standardized aesthetic and movement education. This speeds up the deconstruction of practice that favored the kata and traditional Bushido. In this sense, the objective is to analyze emergency evidence of new cultural codes, characterizing the ethical mitigated, as alternatives to the ethics of Bushido in the traditional sense. To achieve it, it performed a hybrid research in which practitioners of Karate Shotokan are questioned and interviewed from 1st Dan affiliated to the Karate Federation of Rio de Janeiro. Therefore, the study shows that the ethics of Bushido moves toward other values, anchored in the imaginary power of traditional Bushido paving the ground for the legitimization of new values.

Keywords: Karatê. Ethics. Aesthetic. Sense Displacement.

\section{LA MITAD DEL HORIZONTE FUNAKOSHI KARATE DESPORTIVIZADO}

Resumen: El Este Funakoshi proyecta en el karate actual. En este sesgo, la dirección de desplazamiento deportivización generar valores mixtos de Bushido que unen a los valores antiguos y nuevos. Por lo tanto el maestro pierde autonomía en la Federación que tiende a invertir en una educación estética y el movimiento estandarizado. Esto acelera la deconstrucción de la práctica que favoreció el kata y Bushido tradicional. En este sentido, el objetivo es analizar la evidencia de emergencia de nuevos códigos culturales, la caracterización de la ética mitigado, como alternativas a la ética del Bushido en el sentido tradicional. Para lograrlo, se realizó una investigación híbrido en el que se cuestionan y entrevistaron a partir del 1 de Dan afiliado a la Federación de Karate de Río de Janeiro practicantes de Karate Shotokan. Por lo tanto, el estudio muestra que la ética del Bushido se mueve hacia otros valores, anclados en el poder imaginario de Bushido tradicional preparando el terreno para la legitimación de nuevos valores.

Palabras clave: Karate. Ética. Estética. Dirección de Desplazamiento. 